\title{
A CONFIGURAÇÃO DO INTELECTUAL NO ROMANCE S. BERNARDO
}

\section{INTELLECTUAL CONFIGURATION IN THE NOVEL S. BERNARDO}

\author{
Benedito Antunes \\ Universidade Estadual Paulista/CNPq, São Paulo, São Paulo, Brasil \\ benedito.antunes@unesp.br
}

Resumo: O artigo procura caracterizar a voz narrativa do romance $S$. Bernardo, de Graciliano Ramos, como uma consciência crítica que acompanha e avalia os fatos ficcionais, apresentandose, dessa forma, como um intelectual. Seja de forma direta, enquanto narrador ou personagem, seja nas variadas formas de focalização, essa figura está presente em toda a grande literatura e tende a criar uma instância que reflete sobre o objeto da narração, visando à discussão de questões históricas, sociais e políticas abordadas na obra. Seu exame abre perspectivas para a compreensão do contexto sociopolítico representado e do modo de apreender os temas de que se ocupa o autor. No Brasil, a presença do intelectual pode ser observada na obra de clássicos como Machado de Assis, Lima Barreto, Mário de Andrade, Graciliano Ramos, Cyro dos Anjos, mas sua configuração assume particular interesse nos romances que expressam anseios de mudança social e política, como os publicados na década de 1930.

Pallaviras-chave: A representação do intelectual; S. Bernardo; Graciliano Ramos; Romance de 30; Literatura e história

Abstract: This paper tries to characterize the narrator's voice in the novel S. Bernardo by Graciliano Ramos, as a critical conscience which accompanies and evaluates fictional facts, presenting himself as an intellectual. Either in a direct way, as a narrator or character, or in the various forms of focalization, that figure is found out in all great literature and tends to create an instance which reflects on the subject of the narration, aiming at discussing historical, social, political issues broached in the novel. His exam opens perspectives for understanding the represented sociopolitical context and the way of learning the topics broached by the author. In Brazil, the presence of the intellectual may be observed in classic writers' works such as Machado de Assis, Lima Barreto, Mário de Andrade, Graciliano Ramos, Cyro dos Anjos, but his configuration takes on a particular interest in novels which express yearnings for social and political changes, like the ones published in the 1930s.

Keywords: The representation of the intellectual; S.Bernardo; Graciliano Ramos; novel of 1930s; Literature and history 
Quando se lê um dos romances publicados na década de 1930 no Brasil, nota-se invariavelmente a forte tendência de representar e questionar as relações sociais, acenando com alguma perspectiva de superação. Corresponde à proposta literária da chamada segunda fase do Modernismo, em que prevalece, nos termos da feliz formulação de João Luís Lafetá, o projeto ideológico sobre o projeto estético, dominante na década de 1920. Nessa fase, discutem-se "a função da literatura, o papel do escritor, as ligações da ideologia com a arte" (LAFETÁ, 1974, p. 17). Do ponto de vista estético, essa tendência, embora responda à necessidade de se ocupar das condições desiguais de vida social e econômica, nem sempre se concretiza em obras duradouras, que alcançam representar aspectos dessa contradição e não se esgotam no contexto de sua produção. Um modo de perceber a questão é comparar romances com perspectivas semelhantes, mas com resultados diversos em termos de realização estética.

O período é particularmente rico para a criação literária preocupada em denunciar as desigualdades sociais de um país subdesenvolvido, tomando a região Nordeste como microcosmo mais evidente. Só em 1933 são publicados três exemplares daquilo que Luís Bueno chama de "explosão do romance proletário" (2006, p. 159): Cacau, de Jorge Amado, Serafim Ponte Grande, de Oswald de Andrade e Os Corumbas, de Amando Fontes. Tirando o romance de Oswald de Andrade, cujo maior interesse no âmbito político do momento reside no seu prefácio crítico, em que o autor renega a obra, os outros dois ensejam intensa discussão sobre a representação da luta de classes e sua possível superação pela revolução socialista. Para esta abordagem, interessa observar as soluções dadas a esse propósito, acompanhando as personagens que poderiam representar uma espécie de porta-voz dos desígnios do autor.

Com essa finalidade, podem ser comparados os projetos de Jorge Amado e de Graciliano Ramos, que se ocuparam de temas semelhantes em romances publicados nessa época, como Cacau (1933) e Suor (1934), do primeiro, e S. Bernardo (1934), do segundo. Ambos os autores estavam direta ou indiretamente comprometidos com a militância política, contribuindo de alguma forma com o movimento que desembocou na chamada intentona comunista. Ambos foram perseguidos por isso, e as ideias que defenderam nessa circunstância foram objeto de elaboração ficcional, de que servem de exemplo feliz os três romances mencionados. Como os aspectos são múltiplos e as implicações, amplas, elege-se aqui a abordagem da figura que encampa os pressupostos desse tipo de representação, normalmente uma personagem esclarecida, ou mais propriamente um intelectual. Trata-se, em suma, de observar a configuração do intelectual nessas obras, considerando sua visão de mundo e a maneira como sugere formas de superação da desigualdade social por meio da ficção.

Cabe assinalar, inicialmente, que a figura do intelectual na representação literária tende a instaurar um ponto de vista crítico, que concentra a visão de mundo do autor e suas prováveis convicções existenciais, no caso, políticas. Comporta, dessa forma, a dificuldade formal de estabelecer uma interação aceitável entre a matéria narrativa e a consciência crítica sobre ela. Nesse sentido, são sugestivas as perspectivas apresentadas por Edward W. Said (2005), quando trata da representação do intelectual na literatura e considera que ela altera substancialmente a própria representação da realidade social. Segundo o autor, trata-se de "algo que só romances realistas panorâmicos do século XIX podem fazer", isto é, "mostrar intelectuais em ação, envolvidos em numerosas dificuldades e tentações, mantendo ou traindo sua vocação, não como uma tarefa fixa [...], mas como uma experiência concreta constantemente ameaçada pela própria vida moderna" (2005, p. 33). De suas reflexões, interessa, sobretudo, o que diz sobre a atuação independente desse intelectual, que lhe permitiria agir na perspectiva da mudança e não do conformismo em relação a formas sociais tidas como definitivas por determinados setores. Para 
ele, "as representações intelectuais são a atividade em si, dependentes de um estado de consciência que é cética, comprometida e incansavelmente devotada à investigação racional e ao juízo moral", o que "expõe o indivíduo e coloca-o em risco" (SAID, 2005, p. 33).

Apesar das particularidades do contexto a que se refere Said, suas indicações ajudam a perceber a configuração de personagens literárias que concentram o potencial reflexivo de uma obra. A título de exemplo, podem ser recordados alguns aspectos do perfil e do comportamento do Conselheiro Aires, personagem do romance Memorial de Aires, de Machado de Assis, bem como de Gonzaga de Sá e de Belmiro Borba, personagens, respectivamente, de Lima Barreto e Cyro dos Anjos, que permitem compreender traços semelhantes aos estudados pelo intelectual palestino. Não por acaso, as três personagens brasileiras sobrevivem com o salário de um emprego público, o que em princípio as libera do envolvimento com a atividade produtiva da sociedade burguesa. Aires é um diplomata aposentado que viveu no exterior e aparenta condições econômicas superiores à dos outros dois, mas isso não representa nenhuma vantagem material, pois sua preocupação central se volta principalmente para o universo externo a ele. Gonzaga e Belmiro, por sua vez, representam típicos burocratas, cuja atividade não conduz a nada relevante, servindo apenas para manter funcionando uma máquina ironicamente inútil. Eventuais agruras econômicas transparecem no seu cotidiano, mas, assim como ocorre com Aires, não perturbam os indivíduos, que se dedicam a outras ocupações. Do ponto de vista formal, os romances de que são protagonistas fogem ao padrão mimético convencional e se estruturam na forma de um diário para Aires e Belmiro, instaurando, aliás, mais do que casuais semelhanças entre os dois, e de uma biografia para Gonzaga. Nos três casos, a focalização é controlada diretamente pelos narradores, de forma indiscutível no primeiro e no terceiro, em que as personagens anotam suas ações e reflexões, e de forma um tanto ambígua no segundo, em que a personagem biografada é objeto de observação do biógrafo ficcional Augusto Machado. Em comum, os três romances apresentam condições temáticas e formais para que suas personagens centrais gozem de distanciamento para observar suas próprias vidas e o universo social de que participam.

Quando se trata de romances que obedecem a um claro projeto ideológico dos autores, como no caso da produção inicial de Jorge Amado, os temas são tratados diretamente, sem meias-tintas. Em Cacau, a figura do intelectual é representada por José Cordeiro, conhecido como Sergipano, personagem oriunda da classe dominante que, decaída, migra de Sergipe para a região cacaueira da Bahia e se torna um "alugado" do coronel "Mané Frajelo". Nessa condição, passa a atuar de modo a revelar a situação e exploração dos trabalhadores e a alimentar a esperança de que "um dia" a situação mude, isto é, seja alterada pela revolução socialista. Em Suor, essa consciência crítica está dispersa entre algumas personagens que vivem no cortiço conhecido como 68, na Ladeira do Pelourinho. São elas que apresentam alguma informação sobre a luta de classes e ensaiam uma forma de organização revolucionária quando apoiam um movimento grevista e se rebelam contra o proprietário do cortiço e os investigadores. Embora a consciência política pareça mais autêntica no segundo romance, em ambos, na verdade, fica evidente a dificuldade de combinar a perspectiva crítica e revolucionária gestada numa classe para configurar a voz dos oprimidos que, da perspectiva revolucionária, seriam os sujeitos do movimento histórico. Trata-se, em suma, da dificuldade de abrir-se ao outro, especialmente ao proletário, conforme Luís Bueno (2006, p. 243), para compartilhar com ele uma consciência que lhe caberia do ponto de vista histórico, mas que foi produzida em outra classe. 
Em Graciliano Ramos, a mesma questão recebe tratamento de outro tipo. Consciente de que não pode falar pelo outro diretamente, seu narrador busca soluções formais para se aproximar do outro sem negar sua origem de classe e de indivíduo esclarecido. Isso é possível, como se verá adiante, pela imbricação de vozes solidárias. O interesse de examinar a configuração do intelectual em romances engajados como esses reside na possibilidade de se observar, de um lado, o engajamento direto, em que a linguagem literária fica em segundo plano, e, de outro, a linguagem literária oferecendo soluções para que o engajamento se torne mais consistente. Sob esse aspecto, a figura do intelectual nesses romances é um ponto que esclarece a própria questão do engajamento em arte. Dessa forma, essa figura consciente pode ser observada não diretamente em personagens, mas em outros recursos ou técnicas de focalização em que o distanciamento crítico configura uma instância que ultrapassa os limites ficcionais do narrador ou da personagem central, aproximando-se da própria consciência do autor. É o que se verifica em S. Bernardo, de Graciliano Ramos. Cabe recordar, a propósito do narrador desse romance, que mais de um crítico de respeito apontou como falha de composição conceber um escritor refinado na pele de um matuto como Paulo Honório. A perspectiva que será examinada a seguir talvez explique esse ponto, de modo a permitir que a possível falha se torne uma vantagem da representação. Para melhor compreender a questão, observe-se um fragmento das páginas iniciais do romance:

Aqui sentado à mesa da sala de jantar, fumando cachimbo e bebendo café, suspendo às vezes o trabalho moroso, olho a folhagem das laranjeiras que a noite enegrece, digo a mim mesmo que esta pena é um objeto pesado. Não estou acostumado a pensar. Levanto-me, chego à janela que deita para a horta.

$[\ldots]$

Ora vejam. Se eu possuísse metade da instrução de Madalena, encoivarava isto brincando. Reconheço finalmente que aquela papelada tinha préstimo.

O que é certo é que, a respeito de letras, sou versado em estatística, pecuária, agricultura, escrituração mercantil, conhecimentos inúteis neste gênero. Recorrendo a eles, arrisco-me a usar expressões técnicas, desconhecidas do público, e a ser tido por pedante. Saindo daí, a minha ignorância é completa. E não vou, está claro, aos cinquenta anos, munir-me de noções que não obtive na mocidade.

Não obtive, porque elas não me tentavam e porque me orientei num sentido diferente. O meu fito na vida foi apossar-me das terras de S. Bernardo, construir esta casa, plantar algodão, plantar mamona, levantar a serraria e o descaroçador, introduzir nestas brenhas a pomicultura e a avicultura, adquirir um rebanho bovino regular. Tudo isso é fácil quando está terminando e embira-se em duas linhas, mas para o sujeito que vai começar, olha os quatro cantos e não tem em que se pegue, as dificuldades são terríveis (RAMOS, 1981, p. 10-11).

Como se percebe, esta é a cena inicial de $S$. Bernardo, representada no segundo capítulo e que aparecerá algumas vezes ao longo do romance e será retomada no fím, quando o narrador diz: "Vou ficar aqui, às escuras, até não sei que hora, até que, morto de fadiga, encoste a cabeça e descanse uns minutos" (RAMOS, 1981, p. 188). Representa Paulo Honório no tempo presente, quando tenta começar a narração de sua história. Estabelece uma homologia entre as dificuldades que teve para construir a fazenda S. Bernardo - "Tudo isso é fácil quando está terminado e embira-se em duas linhas, mas para o sujeito que vai começar, olha os quatro cantos e não tem em que se pegue, as dificuldades são terríveis" - e as que enfrenta no presente para "construir" o livro S. Bernardo - "suspendo às vezes o trabalho moroso, [...] digo a mim mesmo que esta pena é um objeto pesado. Não estou acostumado a pensar". 
A homologia é forte, porque trata os dois empreendimentos com o mesmo método. $\mathrm{E}$ os dois são igualmente vitais. No caso da fazenda, foi o seu "fito na vida"; com o livro, tenciona "contar a [sua] história" (RAMOS, 1981, p. 10). Apesar disso, as diferenças são enormes: a construção da fazenda é apresentada como um fato passado, embirada "em duas linhas". Já a construção do livro dá-se no presente da escrita e, portanto, está marcada pelas dificuldades "terríveis". Mas não é só isso: as oposições entre tempo passado e tempo presente, entre a velocidade da síntese e a hesitação do trabalho em curso expressa outra oposição, mais funda. Enquanto, num caso, a matéria é objetiva - comprar terras, construir casa, plantar algodão, mamona, levantar serraria e descaroçador etc. - noutro, é subjetiva - narrar fatos que "não revelaria, cara a cara, a ninguém”, e por isso o livro vai ser publicado com pseudônimo.

Há ainda a oposição talvez maior, sobrepondo-se às demais: entre a personagem Paulo Honório e o narrador Paulo Honório. A personagem orientou-se "num sentido diferente"; o narrador está procurando tornar-se pensador - "Não estou acostumado a pensar". Entre um e outro, encontra-se Madalena, a esposa, também ela cumprindo dois papeis: o de esposa do proprietário, mãe do herdeiro etc., de um lado; a mulher que pensa, lê e escreve, de outro. No percurso embirado de sua vida, Paulo Honório tenta incluí-la no universo reificado da matéria objetiva; na busca de sentido para a vida, quando começa a escrever, ela é lembrada como a mulher instruída, e portanto mais próxima de seus ideais: "Se eu possuísse metade da instrução de Madalena, encoivarava isso brincando".

Como foi apontado anteriormente, há aqui, no plano da representação realista, uma aparente contradição, que aliás costuma ser vista como defeito do livro: como uma personagem bruta, que aprendeu "leitura com o Joaquim sapateiro, que tinha uma bíblia miúda, dos protestantes" (RAMOS, 1981, p. 13), se mete a escrever? Nesse ponto, entra a meu ver o engenho do autor: introduzir numa determinada personagem uma consciência que não pode ser sua, mas que instaura a perspectiva adequada para dar vida e sentido crítico ao material narrativo. O efeito não seria da mesma ordem se a consciência proviesse de um narrador externo, onisciente, assim como seria frágil se decorresse de uma voz em primeira pessoa, limitada aos seus parcos recursos ("O que certo é que, a respeito de letras, sou versado em estatística, pecuária, agricultura, escrituração mercantil [...].”). É justamente a coincidência entre uma prática e a reflexão sobre ela que gera a instância intelectual a que estou me referindo.

O procedimento pode ser mais bem compreendido pela descrição feita por Alfredo Bosi a propósito da narração em Vidas secas. O discurso narrativo do romance é o que se chama de indireto livre, combinando a voz objetiva de um narrador externo com a intimidade das personagens. Nesse todo indissolúvel, Bosi percebe a fratura entre as duas vozes, não como defeito, mas como recurso expressivo. O procedimento é visível, por exemplo, quando o narrador de Vidas secas utiliza a forma verbal do condicional para narrar o pensamento de Fabiano. Quando este sonha com o paraíso do tempo das águas, "a expressão verbal desse paraíso, que há de vir um dia, se faz no condicional": "A catinga ressuscitaria, a semente do gado voltaria ao curral, ele, Fabiano, seria o vaqueiro daquela fazenda morta" (BOSI, 1988, p. 11). Nesse recurso, observa Bosi, "de um lado, arma-se uma tática de aproximação com a mente do sertanejo, pois são os desejos de Fabiano que se projetam aqui. Mas, de outro, o modo condicional ou potencial (e não simples futuro do presente) registra a dúvida com que a visão do narrador vai trabalhando o pensamento do vaqueiro" (BOSI, 1988, p. 11). Estabelece-se, então, uma "proximidade em relação ao tema e distância do foco narrativo em relação à consciência da personagem". A combinação desses aspectos, segundo Bosi, é que vai "enformar o realismo crítico de Graciliano". O princípio descrito é de que Graciliano "simpatiza” com o 
homem explorado, mas não considera sua "fala e seus devaneios algo mais do que a voz da inconsciência" (BOSI, 1988, p. 13). Sua concepção crítica da sociedade o leva a emitir juízos sobre o comportamento de Fabiano, mas o faz de dentro, como decorrência de uma íntima integração entre os dois, numa espécie de "certeza compartilhada", que é movida pela solidariedade, caracterizando o que Bosi chama de "simpatia intelectual". Embora o autor aponte "a mediação ideológica do determinismo" separando o escritor da matéria sertaneja, reconhece o "alcance revolucionário" de sua visão, que desconfia do discurso do "civilizado": "Se a voz do iletrado é pobre e partida, a do letrado é oca, se não perigosa". Assim, seu olhar crítico "não favorece nem a linguagem do dominado nem a dos dominantes" (BOSI, 1988, p. 14).

Dessa forma, observa-se, tanto num romance como no outro, um discurso novo, criado não para simplesmente dar voz ao oprimido ou ao proprietário, que não têm a consciência do historiador crítico, mas para introduzir na sua prática a simpatia intelectual, que permitirá compartilhar certezas decorrentes do processo social vivido solidariamente. O procedimento, em S. Bernardo, é visível na ampla discussão do próprio gênero romance. Toda a simulação apresentada no primeiro capítulo, de que iria escrever o livro "pela divisão do trabalho", além de remeter ao processo de criação da fazenda, tem a função de apresentar um conceito de literatura: por meio de preceitos morais, citações latinas, pontuação, ortografia e sintaxe etc., todos imaginavam "contribuir para o desenvolvimento das letras nacionais" (RAMOS, 1981, p. 7). Após essa encenação, Paulo Honório decide iniciar a composição valendo-se de seus próprios recursos e avisa que não pretende "bancar o escritor": "As pessoas que me lerem terão, pois, a bondade de traduzir isto em linguagem literária, se quiserem. Se não quiserem, pouco se perde" (RAMOS, 1981, p. 11). Por esta e pelas demais considerações de método que o narrador vai fazendo ao longo do romance, percebe-se um projeto estético, a busca de uma forma de expressão que corresponda a novas necessidades.

Se o narrador não tem mais função, por ter perdido sua autoridade histórica, como diz Walter Benjamin em seu clássico estudo sobre essa categoria narrativa, a narração faz-se aqui pelo questionamento do próprio discurso narrativo, em busca de uma forma que permita organizar a matéria narrativa. Nesse sentido, é expressiva a maneira como o narrador conclui o segundo capítulo. Antes de exclamar que havia escrito "dois capítulos perdidos", ele declarara que não pretendia "mudar de profissão", isto é, passar de fazendeiro a escritor. A contradição dessa premissa vem no diálogo que se segue, com feição de "monólogo interior": - Então para que escreve! / - Sei lá! (RAMOS, 1981, p. 11). A aparente falta de propósito para escrever é uma atitude, de saída, contraposta à da personagem que construiu S. Bernardo: é pura gratuidade. Como havia dito pouco antes, não iria indagar se o livro the traria "qualquer vantagem, direta ou indireta" (RAMOS, 1981, p. 10).

Como procedimento literário, estamos próximos do adotado por Mário de Andrade em Amar, verbo intransitivo, em que o próprio autor parece sobrepor-se ao narrador quando faz comentários e apreciações sobre o percurso de Fräulein. Ou do adotado por Cyro dos Anjos, em $O$ amanuense Belmiro, em que o narrador reflete sobre o comportamento político de seus amigos. Ou do adotado por Lima Barreto, em Vida e Morte de M. J. Gonzaga de Sá, ao criar um biógrafo que dialoga com o biografado, de forma a apresentar uma espécie de ensaio filosófico literário. Ou ainda do adotado por Machado de Assis, em Memorial de Aires, em que também a personagem reflete sobre o que vive e o que observa, criando uma espécie de segundo plano narrativo. Em todos esses livros, há uma lúcida consciência que organiza a matéria narrativa de forma a sugerir sentidos que vão além do horizonte das personagens. 
No tocante a $S$. Bernardo, porém, é preciso observar o núcleo do conflito que gera a necessidade do livro: a tensão entre Paulo Honório e Madalena. A relação, que aparece na superfície como meramente conjugal, com cenas de ciúmes que lembram o par Bentinho/Capitu, é na verdade a base para a representação de uma contradição social: as relações de produção na sociedade burguesa. Recorde-se que Paulo Honório, no seu empreendedorismo, configura o próprio capital, enquanto Madalena, depois associada a Padilha, representa a contraposição humanista, que se recusa a ser reificada.

O primeiro aspecto que chama a atenção nesse processo, e já foi apontado no início, é a aversão de Paulo Honório pelas letras: "Metam pessoal letrado na apanha da mamona. Hão de ver a colheita" (RAMOS, 1981, p.44). No seu caso, declara: "não tenho o intuito de escrever em conformidade com as regras" (RAMOS, 1981, p. 78). Na sua opinião, instrução nada tem a ver com "leitura de papel impresso". Isso tudo não elimina a expressão de um saber, em linguagem culta. A propósito de sua tentativa de se entender com Madalena, diz: "Tive, durante uma semana, o cuidado de procurar afinar a minha sintaxe pela dela, mas não consegui evitar numerosos solecismos" (RAMOS, 1981, p. 95). Observa-se, assim, que Paulo Honório, enquanto se distancia de Madalena por razões ideológicas, vai se aproximando dela pelo seu saber, pela capacidade de expressão. Parece aplicar-se a esse movimento do narrador o que Antonio Candido observou no estilo do livro que, "graças à secura e violência dos períodos curtos, nos quais a expressão densa e cortante é penosamente obtida, parece indicar essa passagem da vontade de construir à vontade de analisar, resultando um livro direto e sem subterfúgio, honesto como um caderno de notas" (1992, p. 31). O processo se torna intenso, após a morte da esposa, quando ele voluntariamente busca os recursos que ela dominava para traçar o "retrato moral de sua mulher" (RAMOS, 1981, p. 101). Isso fica claro no capítulo 19, quando o narrador retoma o momento da enunciação e se mostra, ao mesmo tempo, irritado e tranquilo, numa espécie de simbiose entre o antes e o depois da mudança:

Agitam-se em mim sentimentos inconciliáveis: encolerizo-me e enterneço; bato na mesa e tenho vontade de chorar.

Aparentemente estou sossegado: as mãos continuam cruzadas sobre a toalha e os dedos parecem de pedra. Entretanto ameaço Madalena com o punho. Esquisito (RAMOS, p. 1981, p. 103).

Mas esse é o tom geral do livro. No detalhe, interessa observar como o narrador, configurado em Paulo Honório, mas mesclado com a consciência crítica do autor, vai introduzindo conceitos, informações e valores na boca das demais personagens. Padilha prega o "extermínio dos burgueses" (RAMOS, 1981, p. 54). O narrador atribui a outros personagens argumentos contra a propriedade, como quando Padilha discursa para Marciano e Casimiro Lopes (RAMOS, 1981, p. 59-60). A certa altura do romance, diz Madalena para defender a tia: "D. Glória vê máquinas e homens que funcionam como máquinas" (RAMOS, 1981, p. 117), em que se observa a sobreposição de perspectivas: D. Glória / Narrador. Na cena do jantar narrada no capítulo 24, toda a discussão entre Padre Silvestre, João Nogueira, Gondim, D. Glória, Madalena e Padilha serve para enunciar os princípios da revolução e do comunismo, evidentemente para serem contestados por Paulo Honório. (- Seria magnífico, interrompeu Madalena. Depois se endireitava tudo. / - Com certeza, apoiou Luís Padilha). Até que Paulo Honório conclui para si: "- Sim senhor, comunista! Eu construindo e ela desmanchando" (RAMOS, 1981, p. 130).

O que vai ficando claro é o processo de identificação cada vez maior entre o narrador explícito (Paulo Honório) e o autor implícito, que representa o historiador crítico, ou o filósofo, 
aquele que reflete e indica mudanças. Só que o procedimento não é desenvolvido de forma direta. Ocorre aquela espécie de solidariedade intelectual, que permite a Paulo Honório caminhar em direção ao seu oposto, como se ele incorporasse o discurso de Madalena. Veja-se a passagem, nesse sentido exemplar, em que recorda a conversa com a esposa e fala como se ela própria falasse: "As casas dos moradores eram úmidas e frias. A família de mestre Caetano vivia num aperto que fazia dó. E o pobre do Marciano tão esbodegado, e tão escavacado, tão por baixo" (RAMOS, 1981, p. 177).

Seja de forma direta, enquanto narrador ou personagem, seja nas variadas formas de focalização, a figura do intelectual tende a criar uma instância que reflete sobre o objeto da narração, visando à discussão de questões históricas, sociais e políticas abordadas nos romances. A análise dessa figura abre perspectivas para a compreensão do contexto sociopolítico representado e do modo de cada autor apreender os temas de que se ocupa. Sua voz expressa anseios de mudança social e política, seja de forma engajada, seja como mera veleidade. No caso de Graciliano, a perspectiva seria revolucionária, mas o narrador, identificado com Paulo Honório, aponta para a impossibilidade de uma mudança radical, atingindo, assim, uma espécie de impasse. Isso significa mais do que uma simples reflexão política, é apresentação das contradições, conduzida pela consciência intelectual que se associa aos atores do processo e lhes dá uma dinâmica só possível na representação literária.

Concluindo, pode-se dizer que Paulo Honório não é apenas Paulo Honório. É um complexo de personagem e consciência que vive e reflete sobre sua experiência. Enquanto a personagem pode dizer que, se fosse recomeçar sua vida, faria tudo igual, o narrador parece mudado. Este não é mais capaz de retomar sua vida. S. Bernardo fazenda, passada a crise, voltará a ser o que era antes, a produzir de forma moderna, perfeitamente integrada ao capitalismo. S. Bernardo livro é o espaço do narrador em crise, que apresenta uma consciência que não volta atrás. Como não pode ir adiante, pois a superação do modo de produção figurada na fazenda não é viável, o narrador fica no impasse: "vou ficar aqui, às escuras, até não sei que hora, até que, morto de fadiga, encoste a cabeça à mesa e descanse uns minutos" (RAMOS, 1981, p. 188).

Com isso, a abertura para o outro, representada inicialmente pela duplicidade do narrador que incorpora no seu discurso perspectivas opostas à sua, instaura um processo em que parece dizer o contrário do que efetivamente diz. Num primeiro plano, defende até o fim a sua propriedade, com todas as implicações inerentes ao regime capitalista. Em segundo plano, resta configurada a possibilidade de sua superação. Como interpreta João Luís Lafetá, "o dínamo não pode existir indefinidamente. Mais do que uma esperança, sua destruição é uma possibilidade concreta e próxima" (LAFETÁ, 1981, p. 202). Isso ocorre graças à incorporação em sua narrativa dos valores contrários representados por Madalena e suas ideias. Nesse movimento, prevalece uma voz que orienta as perspectivas em confronto, instaurando um processo dialético em que as contradições sociais são representadas sem o imperativo de uma atitude maniqueísta que defende a revolução ignorando as condições históricas.

Dessa forma, a cena final, que retoma o início do romance, é cheia de sentido para o leitor. Apresenta-se a ele como um impasse que, no caso, é mais significativo do que possíveis vislumbres de solução. Fosse Graciliano adepto do realismo socialista, a saída poderia ser idealizada, com a indicação de uma sociedade sem classes, ou pelo menos de sua perspectiva, como acontece no desfecho de Cacau, em que Sergipano "partia para a luta de coração limpo e feliz" (AMADO, 1970, p. 220), ou em Suor, com a multidão enfrentando os investigadores motivada pelo grito do militante Álvaro Lima: “- Proletários de todas as nações...” (AMADO, 
1970, p. 339). Mas Graciliano cria um narrador crítico, que conhece a história e sabe de seus limites. Por isso, representa a contradição em toda a sua complexidade, sem se importar com saídas idealizadas. Mas o narrador que fica ali, "às escuras" e "morto de fadiga", não deixa de ser o prenúncio da angústia, que virá a seguir. Trata-se de um belo exemplo de pensamento crítico na ficção.

\section{Referências}

AMADO, J. O país do carnaval. Cacau. Suor. São Paulo: Martins. 1970.

BOSI, A. Céu, inferno: ensaios de crítica literária e ideológica. São Paulo: Ática, 1988.

BUENO, L. Uma história do romance de 30. São Paulo: Edusp; Campinas: Editora da Unicamp, 2006.

CANDIDO, A. Ficção e confissão: ensaios sobre Graciliano Ramos. Rio de Janeiro: 34 Letras, 1992.

LAFETÁ, J. L. 1930: A crítica e o modernismo. São Paulo: Duas Cidades, 1974.

LAFETÁ, J. L. O mundo à revelia. In: RAMOS, Graciliano. São Bernardo. 38.ed. Rio de Janeiro: Record, 1981. p.189-213.

RAMOS, G. S. Bernardo. 38.ed. Rio de Janeiro: Record, 1981.

SAID, E. W. Representações do intelectual: as conferências Reith de 1993. Tradução de Milton Hatoum. São Paulo: Companhia das Letras. 2005.

Recebido em: 01 de agosto de 2020

Aceito em: 01 de dezembro de 2020

Publicado em dezembro de 2020 